\title{
Putative loss of CD83 immunosuppressive activity in long-standing complication-free juvenile diabetic patients during disease progression
}

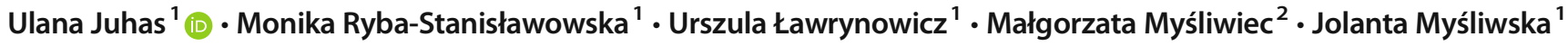

Published online: 2 April 2019

(C) The Author(s) 2019

\begin{abstract}
The CD83 molecule is a known marker of dendritic cell differentiation process, and its soluble form (sCD83) exerts immunosuppressive functions. In our research, we examined whether the sCD83 plasma concentration is impaired in DM1 children and if the expected changes are in line with the disturbed process of monocyte's transformation into $\mathrm{mCD} 83^{+}$monocyte-derived cells. 28 newly diagnosed (ND-DM1) and 30 long-standing (LS-DM1) patients were enrolled into our study. We revealed that the examined cells show a high mCD83 expression level in ND-DM1, which was significantly downregulated by the TNF- $\alpha$ stimulation. The results were in line with those from healthy controls. We also observed that monocyte differentiation process into $\mathrm{CD} 83^{+}$cells was much defective in LS-DM1 children and the mCD83 expression level seems not to be controlled by TNF- $\alpha$. Moreover, the sCD83 level was significantly decreased in plasma from LS-DM1 children and it was negatively related to HbA1c levels, while no correlations were observed between TNF- $\alpha$ plasma concentration or disease duration. Summarizing, our results suggest that reduced sCD83 levels may correspond with a poor metabolic control in LS-DM1 patients and therapeutic administration of this molecule may indicate a new therapy approach in the chronic phase of diabetes.
\end{abstract}

Keywords Soluble CD83 $\cdot$ Type 1 diabetes $\cdot$ Monocyte-derived cells $\cdot$ Membrane CD83

\section{Introduction}

Insulin-dependent type 1 diabetes mellitus (DM1) is a progressive, metabolic disorder that results from accelerated loss

Ulana Juhas

ulana.juhas@gumed.edu.pl

Monika Ryba-Stanisławowska

monika.ryba-stanislawowska@gumed.edu.pl

Urszula Ławrynowicz

urszula.lawrynowicz@gumed.edu.pl

Małgorzata Myśliwiec

malgorzata.mysliwiec@gumed.edu.pl

Jolanta Myśliwska

jolanta.mysliwska@gumed.edu.pl

1 Department of Medical Immunology, Laboratory of Experimental Immunology, Medical University of Gdańsk, Dębinki 1, 80-211 Gdańsk, Poland

2 Department of Paediatrics, Diabetology and Endocrinology, Medical University of Gdańsk, Dębinki 7, 80-211 Gdańsk, Poland of pancreatic $\beta$-cells and impaired insulin production [1]. This long-standing disease is characterized by a low-grade chronic systemic inflammation [2], accompanied by formation of leukocyte infiltrations, and impaired blood flow in microvessels and tissue damage. Those effects may contribute to long-term diabetic complication development [3, 4].

Monocytes, which an enhanced number is observed in peripheral blood of complication-free long-standing DM1 patients $[5,6]$, when activated, may spontaneously secrete high levels of proinflammatory cytokine, TNF- $\alpha[5,7]$, and contribute to the progression of the mentioned degenerative process [8-11]. Three different monocyte subpopulations, according to the CD14 and CD16 surface expression can be distinguished. The main subset is comprised of classical, $\mathrm{CD} 14^{\text {bright }} \mathrm{CD} 16^{-}$cells, while the nonclassical subset consists of $\mathrm{CD} 14{ }^{\mathrm{dim}} \mathrm{CD} 16^{+}$monocytes. The phenotype of the least numerous, intermediate population is $\mathrm{CD} 14^{\text {bright }} \mathrm{CD} 16^{+}[12]$. Depending on microenvironment conditions, monocytes may transform into dendritic cells (MoDCs) and augment in vivo the residual myeloid dendritic cell subset [13].

Among the most characteristic markers of differentiated DCs, one can mention a single-chain glycoprotein member 
of the Ig superfamily $[14,15]$, the membrane CD83 molecule (mCD83) [14]. It is also expressed by many other immune cells [16-22] as well as thymic epithelial cells [23]. The mCD83 may be also detected intracellularly in monocytes, macrophages, and immature DCs, but its surface expression may be induced after LPS activation [24].

A soluble form of the $\mathrm{CD} 83$ molecule ( $\mathrm{SCD} 83$ ) is present in normal human sera $[17,25]$, and it is generated by a proteolytic cleavage of a membrane-bound form. It may be released by activated monocytes, in vitro generated MoDCs as well as, at low levels, peripheral blood CD1c ${ }^{+}$DCs $[17,21]$. Ju et al. concluded that mCD83 levels expressed on human DCs have a crucial meaning in the process of stimulation, while monocytederived SCD83 is involved in the suppression of excessive immune responses [21]. To date, altered sCD83 plasma levels were identified in patients with early rheumatoid arthritis [26, 27], in some haematological malignancies [28], or multiple sclerosis [29]. As far as we know, there are no works that present the sCD83 plasma concentration levels in long-standing diabetic children, who are prone to develop microvascular complications.

In this work, we aimed to answer if the diabetic process may affect the sCD83 plasma levels in juvenile subjects. As the immunoregulatory defects and altered balance between proinflammatory and antiinflammatory factors in DM1 has previously been observed [30-32], we suspected that the sCD83 plasma concentration may be impaired in those patients. We also estimated how the proinflammatory TNF- $\alpha$ affects the differentiation process of monocytes into $\mathrm{CD} 83^{+}$ cells in PBMC cultures.

\section{Materials and methods}

\section{Materials}

58 randomly selected type 1 diabetic juvenile patients (28 newly diagnosed and 30 with long-standing disease) were recruited from the Clinic of Paediatrics, Department of Diabetology and Endocrinology, Medical University of Gdańsk, Poland. The patients with simultaneous vascular complications, hypertension, inflammatory and infectious diseases, or another autoimmune disorder were excluded from the study. Insulin-dependent type 1 diabetes (DM1) was defined in accordance with the American Diabetes Association criteria. In newly diagnosed children (ND-DM1), the blood samples were collected between days 10 and 15 after diagnosis. The control group consisted of 15 ( 7 girls and 8 boys) healthy individuals. The controls were free of autoimmune and infectious diseases. Plasma was separated after centrifugation $(2500 \mathrm{rpm}$ for $15 \mathrm{~min}$ ) from all the patients and stored at $-20^{\circ} \mathrm{C}$. Glycosylated haemoglobin $(\mathrm{HbAlc})$ was measured at the time of collecting blood. The study was approved by the Ethics Committee of The Medical University of Gdańsk
(NKBBN/406/2013) and followed the principles of the Declaration of Helsinki. From all parents of juvenile participants, written informed consent was obtained. General clinical characteristics of examined patients are shown in Table 1.

\section{Cell isolation and culture}

Six ml of venous blood was collected in heparin-containing Vacutainer tubes (BD Biosciences, USA). Peripheral blood mononuclear cells (PBMCs) were isolated by density gradient centrifugation (Histopaque, Sigma-Aldrich, Poland). The PBMCs were cultured in quadruple on 24-well plates at a density of $1 \times 10^{6}$ cells per $1 \mathrm{ml}$ of RPMI 1640 supplemented with $1 \%$ penicillin/streptomycin and 5\% fetal bovine serum (SigmaAldrich, Poland). We used the following pattern of stimulation: 1st and 2nd wells - unstimulated samples; 3rd and 4th wellssamples with addition of TNF- $\alpha$ (BD Biosciences, USA, at the concentration of $10 \mathrm{ng}$ per well). The cells were cultured for 24 and $72 \mathrm{~h}$ at $37{ }^{\circ} \mathrm{C}$ with $5 \% \mathrm{CO}_{2}$. After incubation time plates were washed by cold PBS (without $\mathrm{Ca}^{2+}$ and $\mathrm{Mg}^{2+}$ ) and kept for $10 \mathrm{~min}$ on ice. Well contents were collected and transferred to the cytometric test tubes (BD Biosciences, USA). To remove supernatants, the cells were washed with PBS and centrifuged at $1500 \mathrm{rpm}$ for $7 \mathrm{~min}$ twice.

\section{Flow cytometric analysis}

To distinguish the $\mathrm{CD} 83^{+}$monocyte-derived population, the PBMCs were suspended in $100 \mu \mathrm{l}$ of PBS and labelled by monoclonal antibodies against the following surface markers: CD14 (BD Biosciences, APC Mouse $\operatorname{IgG}_{2 a}$ K), CD16 (BD Biosciences, APC-Cy7 Mouse $\mathrm{IgG}_{1}, \mathrm{~K}$ ), and CD83 (BD Biosciences, PE-Cy7 Mouse $\mathrm{IgG}_{1}, \mathrm{~K}$ ). The samples were incubated in the dark for $30 \mathrm{~min}$ at room temperature, washed with $2 \mathrm{ml} \mathrm{PBS}$, and centrifuged twice (1500 rpm, $6 \mathrm{~min}$ ). The cells were resuspended in $400 \mu \mathrm{l}$ PBS and analyzed by using flow cytometry (LSRII, BD Biosciences, USA). The dot-plots' region including monocyte-derived cells contained typically 4000 of all events. The mean fluorescence intensities (MFI) of CD14, CD16, and CD83 markers were verified. Data were analyzed by FACSDiva software (BD Biosciences, USA). The monocyte-derived cells were identified using expression of CD14/CD16. The cultured CD83 ${ }^{+}$cells were identified using an SSC/CD83 expression parameter. Gates delineating positive staining were set on the basis of isotype control staining.

\section{Measurement of sCD83 and TNF-a plasma concentration}

The plasma concentration of TNF- $\alpha$ and SCD83 in the DM1 patients $(n=58)$ and healthy controls $(n=15)$ was quantified using a commercial Quantikine HS ELISA test from R\&D Systems (USA) and ELISA kit from Aviscera 
Table 1 General clinical and biochemical characteristic of the healthy controls and DM1 subjects

\begin{tabular}{llll}
\hline Parameters & Healthy controls $(n=15)$ & LS-DM1 $(n=30)$ & ND-DM1 $(n=28)$ \\
\hline Sex $(\mathrm{F} / \mathrm{M})$ & $7 / 8$ & $15 / 15$ & $13 / 15$ \\
Age $($ years $)$ & $12.2 \pm 3.49$ & $13.25 \pm 3.86$ & $10.46 \pm 3.8$ \\
Disease duration & - & $5.66 \pm 3.82$ & 0 \\
HbA1c $(\%)$ & - & $8.38 \pm 1.45$ & $11.27 \pm 2.26$ \\
BMI $\left(\mathrm{kg} / \mathrm{m}^{2}\right)$ & $19.4 \pm 2.06$ & $21.79 \pm 4.97$ & $18.74 \pm 3.98$ \\
sCD83 $(\mathrm{pg} / \mathrm{ml})$ & $35.70 \pm 23.46$ & $8.84 \pm 9.46^{*}$ & $35.3 \pm 33.45$ \\
TNF- $\alpha(\mathrm{pg} / \mathrm{ml})$ & $0.79 \pm 0.25$ & $1.79 \pm 0.94^{* *}$ & $2.55 \pm 0.98^{* *}$ \\
\hline
\end{tabular}

Data are presented as mean \pm SD. The Mann-Whitney $U$ test was used to calculate the differences between groups. $N D$-DM1 newly diagnosed insulin-dependent diabetes type 1 patients, $L S$ - $D M 1$ long-standing complication-free insulin-dependent diabetes type 1 patients. ${ }^{*} p<0.0001, * * p<0.00001$ - comparison between the LS-DM1/NDDM1 patients and healthy controls
Bioscience (USA). The minimum detectable concentration for TNF- $\alpha$ and $\mathrm{sCD} 83$ was $0.106 \mathrm{pg} / \mathrm{ml}$ and $3.125 \mathrm{pg} / \mathrm{ml}$ respectively.

\section{Statistical analysis}

STATISTICA ver. 12 (StatSoft Inc., USA) was used for all the statistical analysis. Data comparison between the groups was done with the Mann-Whitney $U$ test. The Wilcoxon signedrank test was used for paired data comparison among the groups. Correlations were assessed using Spearman's rank test. The results were presented as a mean \pm standard deviation or median and 25 th/75th percentiles. $P$ values less than 0.05 were considered as significant.

\section{Results}

\section{Reduced sCD83 plasma concentration level in long-standing DM1 juvenile patients}

The concentration level of the sCD83 in plasma of patients with long-standing diabetes mellitus type 1 (LS-DM1, $n=28$ ) were statistically lower $(p=0.00007)$ in comparison with the healthy controls $(n=15)$ and newly diagnosed children (ND-DM1, $n=$ $28, p=0.00001)$. No significant differences in the sCD83 plasma levels were found between ND-DM1 children and healthy controls $(p=0.79)$. Both LS-DM1 $(p=0.000002)$ and ND-DM1 children $(p=0.000000004)$ showed statistically higher TNF- $\alpha$ plasma concentration in comparison with the healthy volunteers. ND-DM1 children showed higher TNF- $\alpha$ plasma concentration in comparison with LS-DM1 children $(p=0.00059)$.

When comparing the sCD83 plasma level with TNF- $\alpha$ plasma concentration in ND-DM1 children, we found a significant positive relationship $(r=0.399, p=0.036)$. Moreover, the LS-DM1 patients with a lower SCD83 plasma level showed higher HbA1c $(r=-0.473, p=0.01)$. We did not find any significant correlation between plasma SCD83 and the patients' age or duration of the disease in DM1 children (Table 2, Fig. 1).

\section{Effectiveness of monocytes differentiation into the $\mathrm{mCD} \mathrm{B}^{+}$cells in PBMC cultures of the LS-DM1 patients}

In the healthy controls $(n=11)$, after 72-h-lasting PBMC in vitro culture, most of the examined cells in the monocytic gate (the median frequency of these cells was 70.49) showed
Table 2 Relationship between the SCD83 plasma concentration levels and the values of basic clinical and biochemical parameters in DM1 children

\begin{tabular}{|c|c|c|c|c|}
\hline \multirow[t]{2}{*}{ Clinical and biochemical parameters } & \multicolumn{2}{|l|}{ LS-DM1 } & \multicolumn{2}{|l|}{ ND-DM1 } \\
\hline & $R$ Spearman & $p$ & $R$ Spearman & $p$ \\
\hline TNF- $\alpha(\mathrm{pg} / \mathrm{ml})$ & -0.073 & 0.71 & 0.399 & 0.036 \\
\hline $\operatorname{HbA1c}(\%)$ & -0.473 & 0.01 & 0.07 & 0.73 \\
\hline Age (years) & -0.178 & 0.37 & -0.006 & 0.97 \\
\hline Disease duration (years) & -0.045 & 0.82 & - & - \\
\hline
\end{tabular}

Results were calculated with Spearman's rank test 
surface expression of both CD14 and CD16 markers as well as the CD83 molecule. We have also observed that 72-h-lasting PBMC culture is a favorable condition for the $\mathrm{CD} 83^{+}$cell differentiation in ND-DM1 examined children $(n=10)$ (median percentage of $\mathrm{CD}^{+} 3^{+}$cells was 72.1). In the LS-DM1 patients $(n=30)$, the same PBMC culture setting allowed the differentiation of the much less $\mathrm{CD} 3^{+}$cells in comparison with the healthy controls (median value was 14.82). The results are presented in Table 3.

We also examined the surface mCD 83 kinetic expression, to check if there is an upward trend in the production of this important molecule in non-stimulated PBMC in vitro cultures. The mCD83 surface expression, defined as MFI, was examined at two time checkpoints: 24 and $72 \mathrm{~h}$ in unstimulated
Fig. 1 Relationship between the plasma level of SCD83 and TNF$\alpha / \mathrm{HbA} 1 \mathrm{c}$ in the ND-DM1 and LS-DM1 patients. The Spearman test was used to calculate the strength of correlation (a). The correlation between the sCD83 and TNF- $\alpha$ plasma levels in NDDM1 ( $r=0.399 ; p=0.036),(b)$.

The correlation between the sCD83 and HbA1c levels in LSDM1 $(r=-0.473 ; p=0.01)$

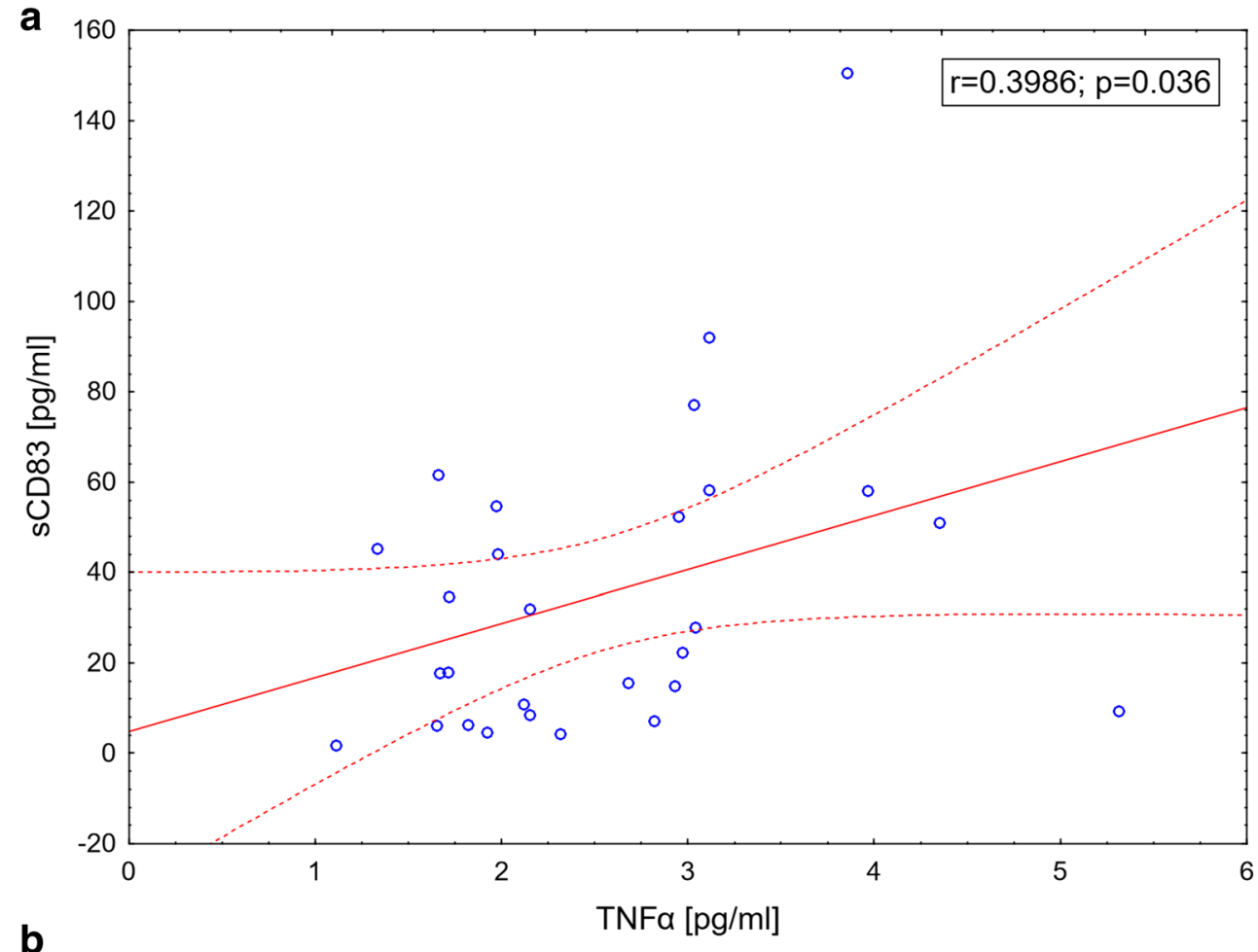

b

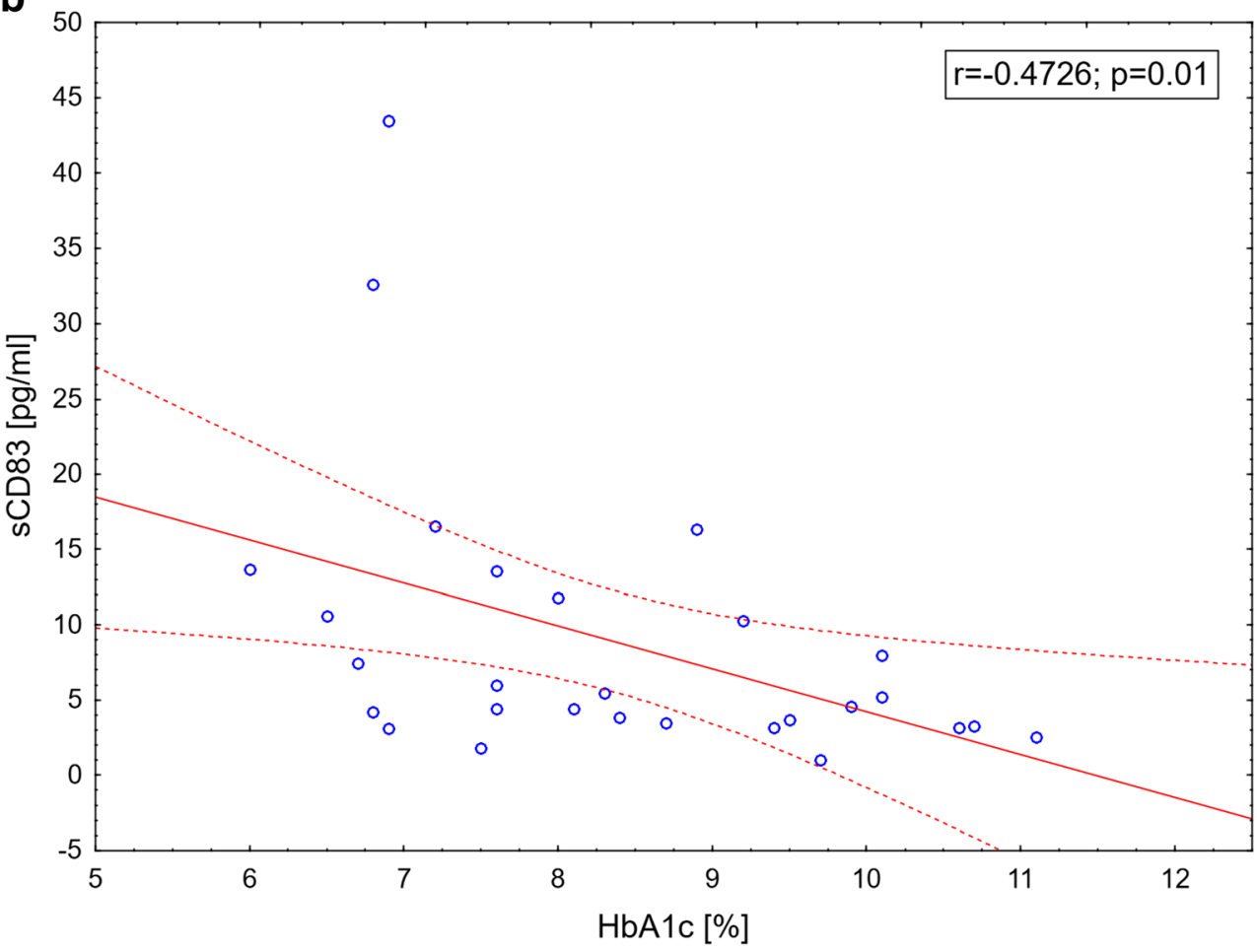


Table 3 Percentage of the CD83 ${ }^{+}$examined cells from 72-h-lasting, unstimulated or TNF- $\alpha$-treated PBMC culture in the healthy controls $(n=10)$, ND-DM1 $(n=10)$ and LS-DM1 $(n=28)$ children

\begin{tabular}{|c|c|c|c|c|c|c|c|c|}
\hline & Healthy controls & ND-DM1 & LS-DM1 & P1 & P2 & P3 & P4 & P5 \\
\hline Unstimulated PBMC & $70.49(56.01 / 73.54)$ & $72.1(65.71 / 75.33)$ & $14.82(2.06 / 55.71)$ & 0.6 & 0.00065 & 0.0033 & 0.015 & 0.0018 \\
\hline TNF- $\alpha$ treated PBMC & $38.89(23.74 / 46.82)$ & $52.57(43.63 / 58.11)$ & $10.69(0.72 / 33.03)$ & 0.01 & 0.0038 & - & - & - \\
\hline
\end{tabular}

Data are presented as median and 25 th $/ 75$ th percentile. The level of significance was set at $p<0.05$. The Mann-Whitney $U$ test was used to calculate the differences between the groups. The nonparametric Wilcoxon test was used for comparison of paired data among the groups. P1/P2 comparison of examined $\mathrm{CD} 3^{+}$cell percentages of unstimulated/TNF- $\alpha$-treated 72-h-lasting PMBC cultures between ND-DM1/LS-DM1 children and healthy controls. P3/P4/P5 comparison of examined $\mathrm{CD} 83^{+}$cell percentages between unstimulated and TNF- $\alpha$-treated 72 -h-lasting PBMC cultures in the ND-DM1/LS-DM1 patients/healthy controls

PBMC culture. Results showed that the mCD83 MFI level significantly increased from 24 to 72 -h cultures in all examined children.

The effect of TNF- $\alpha$ stimulation on the mCD83 molecule expression on the examined cells was also analyzed. Our results showed the reduction of the examined $\mathrm{CD} 3^{+}$cell percentages in all the study groups, as well as the mCD83 surface expression in both the healthy controls and ND-DM1 children. In the LS-DM1 patients, the differentiation process was not affected by TNF- $\alpha$ addition. Results are shown in Table 4.

\section{Discussion}

Upregulation of the surface mCD83 expression levels is a typical feature of the dendritic cells (DCs) differentiation process [14]. The CD83 is also expressed in monocytes, macrophages, or immature dendritic cells. Cao et al. suggested that the CD83 is stably expressed only on the surface of matured, activated DCs, in contrast to activated monocytes, which transiently express this molecule [24].

The soluble form of this molecule, the sCD83, is present in normal human serum [17] and may exert the immunosuppressive functions $[17,21]$. The sCD83 binds with high affinity to the TLR4 coreceptor MD-2 (myeloid differentiation factor-2), which creates the TLR4/MD-2 complex. The interaction between the MD-2 and sCD83 may switch the inflammatory profile into an antiinflammatory one and effectively inhibit $\mathrm{T}$ cell activation [33].

There are few works supporting the protective role of the sCD83 molecule. Zinser et al. have demonstrated that the sCD83 may highly decrease the brain and spinal cord leukocyte infiltration process in a murine model of autoimmune encephalomyelitis. The authors confirmed the suppressive role of the $\mathrm{sCD} 83$ in vivo and suggested its potential to be used as a new therapeutic tool [34]. In addition, the study of Ge et al. confirmed that the sCD83 safely contributes to the tolerance development in case of cardiac allograft rejection [35]. Moreover, its beneficial role in corneal allograft survival and Foxp $3^{+}$T cell upregulation was also determined [36].

Results of Ju et al. led to a conclusion that mCD83 derived from human DCs has a crucial meaning in the stimulation process while sCD83 released by monocyte-derived cells seems to be involved in suppression development [21]. Our study has shown that in all the examined patients, monocytes from PBMC cultures, not stimulated with exogenous cytokines, were able to show a surface CD83 expression and it was upregulated between 24 and $72 \mathrm{~h}$ of incubation. Interestingly, its levels were much reduced in the LS-DM1 patients, while in the ND-DM1 subjects, it was upregulated

Table 4 mCD83 molecule surface expression on the CD83 ${ }^{+}$examined cells from 24 - and 72-h-lasting (unstimulated or TNF- $\alpha$ treated) PBMC culture in the healthy controls $(n=10)$, ND-DM1 $(n=10)$ and LS-DM1 $(n=28)$ children

\begin{tabular}{|c|c|c|c|c|c|c|c|c|}
\hline & Healthy controls & ND-DM1 & LS-DM1 & P1 & $\mathrm{P} 2$ & P3 & $\mathrm{P} 4$ & P5 \\
\hline $24 \mathrm{~h}$ & $1.90(1.64 / 2.30)$ & $2.53(2.35 / 3.38)$ & $1.80(1.27 / 2.19)$ & 0.003 & 0.005 & 0.00002 & 0.00079 & 0.5 \\
\hline $72 \mathrm{~h}$ & $7.99(7.10 / 9.68)$ & $10.52(9.51 / 13.63)$ & $3.43(2.18 / 5.08)$ & - & - & - & 0.02 & 0.0015 \\
\hline \multirow[t]{2}{*}{$72 \mathrm{~h}(\mathrm{TNF}-\alpha)$} & $2.33(1.69 / 2.72)$ & $2.94(2.18 / 3.19)$ & $2.28(1.8 / 4.18)$ & P6 & & P7 & P8 & \\
\hline & & & & 0.003 & & 0.005 & 0.5 & \\
\hline
\end{tabular}

Data are presented as median and $25 \mathrm{th} / 75$ th percentile. The level of significance was set at $p<0.05$. The Mann-Whitney $U$ test was used to calculate the differences between the groups. The nonparametric Wilcoxon test was used for comparison of paired data among the groups. $P 1 / P 2 / P 3$ comparison of the CD83 molecule expression levels (MFI) on examined CD83 ${ }^{+}$cells between 24 and $72 \mathrm{~h}$ of unstimulated PMBC cultures in the healthy controls/NDDM1/LS-DM1 children. P4/P5 comparison of the mCD83 molecule expression levels (MFI) on examined CD83 $3^{+}$cells after 24 and $72 \mathrm{~h}$ of unstimulated PBMC cultures between the healthy controls and ND-DM1/LS-DM1 children. P6/P7/P8 comparison of the mCD83 molecule expression levels (MFI) on the examined $\mathrm{CD}_{3} 3^{+}$cells between unstimulated and TNF- $\alpha$-treated 72-h-lasting PBMC cultures in the healthy controls, ND-DM1, and LS-DM1 children 
in comparison with the healthy controls. Additionally, we have revealed a reduction in the number of the cultured monocyte-derived $\mathrm{CD} 83^{+}$cells $\left(\mathrm{moCD} 83^{+}\right)$in the LS-DM1 group. Our in vitro study revealed that the TNF- $\alpha$ stimulation had no significant impact on the mCD83 monocytes' surface expression in LS-DM1, while it significantly worsened the mCD83 levels on monocytes from the ND-DM1 juveniles and healthy controls.

As far as we know, there are no studies showing altered sCD83 plasma levels in the DM1 juvenile patients, depending on their stage of the disease. The SCD83 plasma concentration was much more reduced in the LS-DM1 subjects than in the healthy ones, and it was coincident with the higher $\mathrm{HbAlc}$ rates. In contrast, the elevated SCD83 levels were observed in some immune disorders. The sCD83 has been suggested as a potential marker for disease activity in multiple sclerosis [11], and others proposed it could modulate an enhanced immune response in rheumatoid arthritis $[12,13]$. Moreover, its prognostic significance was suggested in some haematological malignancies [28].

Surprisingly, we have shown TNF- $\alpha$ plasma concentration coincidence with the sCD83 levels in the ND-DM1 patients. So far, it's hard to explain this observation, but, we suppose it may be connected with the process of monocyte activation and the autocrine loop effect of those molecules. Previously, an enhanced number of the CD16 monocytes producing TNF- $\alpha$ [5] in diabetic children was revealed [6] and the SCD83 may be released from activated monocytes and the monocyte-derived dendritic cells (MoDCs) [17, 21, 37]. The study of Chen et al. showed that the CD83 counter receptor is mainly expressed on monocytes [38] and in vitro stimulation of $\mathrm{CD} 14^{+}$monocytes with the sCD83 increases not only the antiinflammatory IL-10 but also proinflammatory TNF- $\alpha$ production [33]. Others claimed that PGE2 (Prostaglandin E2) production increases in SCD83-stimulated monocytes, while no enhanced IL-10/ TGF- $\beta$ release was noted [38]. We conclude that the elevated TNF- $\alpha$ plasma levels in ND-DM1 children might in turn diminish the monocyte $\mathrm{mCD} 83$ production, a putative source of $\mathrm{sCD} 83$, as the disease develops. On the other hand, a possible role of enhanced TNF- $\alpha$ production on the $\mathrm{mCD} 83$ receptor cleavage in PBMC cultures ought to be taken into account, but further research should be performed.

Taking into account a chronic and inflammatory character of type 1 diabetes revealed a decrease in the sCD83 levels and defective upregulation of the mCD83 levels on the cultured monocyte-derived cells, our results may indicate loss of the CD83 role as an immunosuppressive agent during disease progression. We propose that the $\mathrm{sCD} 83$ administration may have a potential to indicate a new therapy approach of longterm diabetes. This assumption should be confirmed by further in vitro studies.
Acknowledgments This work was supported by the State Committee for Scientific Research ST28 (Medical University of Gdańsk, Poland).

\section{Compliance with ethical standards}

The study was approved by the Ethics Committee of The Medical University of Gdańsk (NKBBN/406/2013) and followed the principles of the Declaration of Helsinki. From all the parents of juvenile participants, written informed consent was obtained.

Conflict of interest The authors declare that they have no conflict of interest.

Open Access This article is distributed under the terms of the Creative Commons Attribution 4.0 International License (http:// creativecommons.org/licenses/by/4.0/), which permits unrestricted use, distribution, and reproduction in any medium, provided you give appropriate credit to the original author(s) and the source, provide a link to the Creative Commons license, and indicate if changes were made.

\section{References}

1. Atkinson MA, Eisenbarth GS, Michels AW. Type 1 diabetes. Lancet. 2014;383:69-82.

2. Alexandraki KI, Piperi C, Ziakas PD, Apostolopoulos NV, Makrilakis K, Syriou V, et al. Cytokine secretion in long-standing diabetes mellitus type 1 and 2: associations with low-grade systemic inflammation. J Clin Immunol. 2008;28:314-21.

3. Navarro-González JF, Mora-Fernández C, Muros de Fuentes M, García-Pérez J. Inflammatory molecules and pathways in the pathogenesis of diabetic nephropathy. Nat Rev Nephrol. 2011;7:327740 .

4. Rangasamy S, McGuire PG, Franco Nitta C, Monickaraj F, Oruganti SR, Das A. Chemokine mediated monocyte trafficking into the retina: role of inflammation in alteration of the bloodretinal barrier in diabeticretinopathy. PLoS One. 2014;20(9): e108508.

5. Myśliwska J, Smardzewski M, Marek-Trzonkowska N, Myśliwiec M, Raczyńska K. Expansion of CD14+CD16+ monocytes producing TNF- $\alpha$ in complication-free diabetes type 1 juvenile onset patients. Cytokine. 2012;60:309-17.

6. Ryba-Stanisławowska M, Myśliwska J, Juhas U, Myśliwiec M. Elevated levels of peripheral blood CD14bright CD16+ and CD14dim CD16+ monocytes may contribute to the development of retinopathy in patients with juvenile onset type 1 diabetes. APMIS. 2015;123:793-9.

7. Belge KU, Dayyani F, Horelt A, Siedlar M, Frankenberger M, Frankenberger B, et al. The proinflammatory CD14+CD16+ $\mathrm{DR}++$ monocytes are a major source of TNF. J Immunol. 2002;168:3536-42.

8. Zorena K, Myśliwska J, Myśliwiec M, Balcerska A, Hak Ł, Lipowski P, et al. Serum TNF-alpha level predicts nonproliferative diabetic retinopathy in children. Mediat Inflamm. 2007;2007: 92196.

9. Schram MT, Chaturvedi N, Schalkwijk C, Giorgino F, Ebeling P, Fuller JH, et al. Vascular risk factors and markers of endothelial function as determinants of inflammatory markers in type 1 diabetes. Diabetes Care. 2003;26:2165-73.

10. Myśliwiec M, Balcerska A, Zorena K, Kamińska H, Nowacka M, Sibińska $\dot{Z}$, et al. Relationship between the level of TNF $\alpha$, IL6 and risk of renal proximal tubules damage in children with newly diagnosed diabetes mellitus type 1. Pol J Environ Stud. 2005;14:292-5. 
11. Mysliwiec M, Zorena K, Balcerska A, Mysliwska J. Does tumor necrosis factor- $\alpha$ preceed occurrence of microalbuminuria in type 1 diabetes mellitus children? J Polish Diabetol Assoc. 2006;3:131-6.

12. Ziegler-Heitbrock L, Hofer TP. Toward a refined definition of monocyte subsets. Front Immunol. 2013;4:23.

13. Lutz MB, Schuler G. Immature, semi-mature and fully mature dendritic cells: which signals induce tolerance or immunity? Trends Immunol. 2002;23:445-9.

14. Zhou LJ, Tedder TF. Human blood dendritic cells selectively express CD83, a member of the immunoglobulin superfamily. $\mathrm{J}$ Immunol. 1995; 154:3821-35.

15. Zhou LJ, Schwarting R, Smith HM, Tedder TF. A novel cell-surface molecule expressed by human interdigitating reticulum cells, Langerhans cells, and activated lymphocytes is a new member of the Ig superfamily. J Immunol. 1992;149:735.

16. Gregori S, Tomasoni D, Pacciani V, Scirpoli M, Battaglia M, Magnani CF, et al. Differentiation of type $1 \mathrm{~T}$ regulatory cells (Tr1) by tolerogenic DC-10 requires the IL-10-dependent ILT4/ HLA-G pathway. Blood. 2010;116:935-44.

17. Hock BD, Kato M, McKenzie JL, Hart DN. A soluble form of CD83 is released from activated dendritic cells and B lymphocytes, and is detectable in normal human sera. Int Immunol. 2001;13:95967.

18. Yamashiro S, Wang JM, Yang D, Gong WH, Kamohara H, Yoshimura T. Expression of CCR6 and CD83 by cytokineactivated human neutrophils. Blood. 2000;96:3958-63.

19. Mailliard RB, Alber SM, Shen H, Watkins SC, Kirkwood JM, Herberman RB, et al. IL-18-induced CD83+CCR7+ NK helper cells. J Exp Med. 2005;202:941-53.

20. Wolenski M, Cramer SO, Ehrlich S, Steeg C, Fleischer B, von Bonin A. Enhanced activation of CD83-positive T cells. Scand J Immunol. 2003;58:306-11.

21. Ju X, Silveira PA, Hsu WH, Elgundi Z, Alingcastre R, Verma ND, et al. The analysis of CD83 expression on human immune cells identifies a unique $\mathrm{CD} 83+$-activated $\mathrm{T}$ cell population. $\mathrm{J}$ Immunol. 2016;197:4613-25.

22. Doebbeler M, Koenig C, Krzyzak L, Seitz C, Wild A, Ulas T, et al. CD83 expression is essential for Treg cell differentiation and stability. JCI Insight. 2018;3:99712.

23. Fujimoto Y, Tu L, Miller AS, Bock C, Fujimoto M, Doyle C, et al. CD83 expression influences CD4+ T cell development in the thymus. Cell. 2002;108:755-67.

24. Cao W, Lee SH, Lu J. CD83 is preformed inside monocytes, macrophages and dendritic cells, but it is only stably expressed on activated dendritic cells. Biochem J. 2005;385:85-93.

25. Lundell AC, Adlerberth I, Lindberg E, Karlsson H, Ekberg S, Aberg N, et al. Increased levels of circulating soluble CD14 but not CD83 in infants are associated with early intestinal colonization with Staphylococcus aureus. Clin Exp Allergy. 2007;37:62-71.

26. Kristensen AM, Stengaard-Pedersen K, Hetland ML, HørslevPetersen K, Junker P, Østergaard M, et al. Expression of soluble
CD83 in plasma from early-stage rheumatoid arthritis patients is not modified by anti-TNF- $\alpha$ therapy. Cytokine. 2017;96:1-7.

27. Hock BD, O'Donnell JL, Taylor K, Steinkasserer A, McKenzie JL, Rothwell AG, et al. Levels of the soluble forms of CD80, CD86, and CD83 are elevated in the synovial fluid of rheumatoid arthritis patients. Tissue Antigens. 2006;67:57-60.

28. Hock BD, Haring LF, Steinkasserer A, Taylor KG, Patton WN, McKenzie JL. The soluble form of CD83 is present at elevated levels in a number of hematological malignancies. Leuk Res. 2004;28:237-41.

29. Karampoor S, Zahednasab H, Etemadifar M, Keyvani H. The levels of soluble forms of CD21 and CD83 in multiple sclerosis. J Neuroimmunol. 2018;320:11-4.

30. Rabinovitch A. Immunoregulatory and cytokine imbalances in the pathogenesis of IDDM. Therapeutic intervention by immunostimulation? Diabetes. 1994;43:613-21.

31. Stechova K, Bohmova K, Vrabelova Z, Sepa A, Stadlerova G, Zacharovova $\mathrm{K}$, et al. High T-helper-1 cytokines but low Thelper-3 cytokines, inflammatory cytokines and chemokines in children with high risk of developing type 1 diabetes. Diabetes Metab Res Rev. 2007;23:462-71.

32. Alnek K, Kisand K, Heilman K, Peet A, Varik K, Uibo R. Increased blood levels of growth factors, proinflammatory cytokines and Th17 cytokines in patients with newly diagnosed type 1 diabetes. PLoS One. 2015;10:e0142976.

33. Horvatinovich JM, Grogan EW, Norris M, Steinkasserer A, Lemos $\mathrm{H}$, Mellor AL, et al. Soluble CD83 inhibits T cell activation by binding to the TLR4/MD-2 complex on CD14+ monocytes. J Immunol. 2017;198:2286-301.

34. Zinser E, Lechmann M, Golka A, Lutz MB, Steinkasserer A. Prevention and treatment of experimental autoimmune encephalomyelitis by soluble CD83. J Exp Med. 2004;200:345-51.

35. Ge W, Arp J, Lian D, Liu W, Baroja ML, Jiang J, et al. Immunosuppression involving soluble CD83 induces tolerogenic dendritic cells that prevent cardiacallograft rejection. Transplantation. 2010;90:1145-56.

36. Bock F, Rössner S, Onderka J, Lechmann M, Pallotta MT, Fallarino $\mathrm{F}$, et al. Topical application of soluble CD83 induces IDO-mediated immune modulation, increases Foxp $3+\mathrm{T}$ cells, and prolongs allogeneic corneal graft survival. J Immunol. 2013;191:1965-75.

37. Sénéchal B, Boruchov AM, Reagan JL, Hart DN, Young JW. Infection of mature monocyte-derived dendritic cells with human cytomegalovirus inhibits stimulation of T-cell proliferation via the release of soluble CD83. Blood. 2004;103:4207-15.

38. Chen L, Zhu Y, Zhang G, Gao C, Zhong W, Zhang X. CD83stimulated monocytes suppress $\mathrm{T}$-cell immune responses through production of prostaglandin E2. Proc Natl Acad Sci U S A. 2011;108:18778-83.

Publisher's note Springer Nature remains neutral with regard to jurisdictional claims in published maps and institutional affiliations. 